\title{
Evidence for Past Life on Early Mars: How the Evidence Stands
}

\author{
Everett K. Gibson
}

Astromaterials Research Office, NASA Johnson Space Center, Mail Code SR, Houston, Texas 77058, USA

Kathie L. Thomas-Keprta

Lockheed Martin Space Operations, Mail Code C-23, Houston, Texas 77058, USA

\section{Simon J. Clemett}

Lockheed Martin Space Operations, Mail Code C-23, Houston, Texas 77058, USA

\section{David S. McKay}

Astromaterials Research Office, NASA Johnson Space Center, Mail Code SR, Houston, Texas 77058, USA

Christopher Romanek

Savannah River Ecology Laboratory, Drawer E, University of Georgia, Aiken SC 29802, USA

\author{
Susan J. Wentworth \\ Lockheed Martin Space Operations, Mail Code C-23, Houston, Texas \\ 77058, USA
}

\begin{abstract}
Martian Meteorite ALH84001 contains four unusual features which have been interpreted as possible signatures of relic biogenic activity. After six years of intense study by the world's scientific community, the current status of the biogenic hypothesis is reviewed and shown to still be valid. Furthermore additional features have been observed in two younger Martian meteorites. The strongest argument for possible evidence of biogenic activity within the ALH84001 meteorite is the presence of truncated hexa-octahedral magnetite crystals which are only known on Earth to be the products of biology.
\end{abstract}

\section{Introduction}

Analysis of the Martian meteorite Allan Hills 84001 led McKay et al. (1996) to suggest that primitive life existed on Mars approximately 3.9 to 4 billion years ago. The four lines of evidence include: (1) low temperature carbonate 
globules with complex non-equilibrium chemical zoning; (2) indigenous complex aromatic hydrocarbons spatially associated with the carbonate globules; (3) morphological features interpreted as the fossilized remnants of microorganisms; and, (4) magnetite crystals with unusual chemical and physical properties, only known to occur on Earth through biogenic activity. Of these lines of evidence, the magnetite crystals have been the focus of the most recent research and controversy. While alternative explanations have been proposed to explain the individual features noted above, the biogenic hypothesis still remains the only one consistent with all the observed features.

\section{The Four Lines of Evidence}

Below we discuss the four lines of evidence in support of the biogenic hypothesis for Martian meteorite ALH84001.

\subsection{Low Temperature Carbonate Globules}

ALH84001 contains carbonate globules that comprise approximately one volume percent of the meteorite (McKay et al. 1996). The formation temperature of these globules was initially proposed to be no higher than $80^{\circ} \mathrm{C}$ (Romanek et al. 1994). However, subsequent work initially suggested that they were formed at high-temperatures $\left(>600^{\circ} \mathrm{C}\right)$ inconsistent with microbial life (Harvey \& McSween 1996; Bradley et al. 1996; Brearley 1998; Kozio \& Brearley 2002). Recently however, paleomagnetic data from Kirschvink et al. (1997) suggested the globules had never been heated above $40^{\circ} \mathrm{C}$. Step-wise heating of the globules in association with noble gas measurements indicated that the globules have not experienced temperatures above $200^{\circ} \mathrm{C}$ over the 3.9 billion year history of the carbonate globule (Bogard \& Garrison 1998). Oxygen isotopic compositions associated with low-temperature processes $\left(<100-200^{\circ} \mathrm{C}\right)$ were noted for carbonate globules (Valley et al. 1997; Eiler et al. 2002). Greenwood \& McKeegan (2002) noted silica-cross cutting carbonate globules had oxygen isotopic compositions indicating maximum temperatures of $75-95^{\circ} \mathrm{C}$ and additional silica $/ \mathrm{SiO}_{2}$-rich glass compositions suggested formation temperatures of $25-40^{\circ} \mathrm{C}$. From these results, we argue that the ALH84001 carbonate globules not only formed at low temperatures but were not heated by shock impact during their residence on or ejection from Mars.

\subsection{Indigenous Organic Matter}

Clemett et al. (1998) demonstrated the presence of indigenous complex aromatic organic material spatially associated with the ALH84001 carbonate globules. While some terrestrial contaminants may also be present within the meteorite as a consequence of their residence in Antarctica, the indigenous nature of the aromatic hydrocarbons has been confirmed by carbon isotope measurements. Jull et al. $(1998,2000)$ noted that there were indigenous reduced carbon components within ALH84001 which did not contain terrestrial ${ }^{14} \mathrm{C}$ contamination nor are they simply the product of catalytic reactions during thermal decomposition of carbonate as has been suggested by McCollum (2003), since they do not share the same carbon isotopic composition as the host carbonate. 


\subsection{Morphological Features}

Features described as possible biogenic microfossils have been identified in Martian meteorites ALH84001, Nakhla, and Shergotty (Gibson et al. 2001). However, present day terrestrial biogenic contaminants have also been observed in all Martian meteorites examined to date (Steele et al. 2000). Hence, it is unclear if the purported microfossils in these meteorites have a Martian or terrestrial origin. Further work, including correlated isotopic analysis, will help constrain the origin of these features.

\subsection{Magnetite Crystals}

Carbonate globules in ALH84001 consist of an optically golden-colored core concentrically zoned in $\mathrm{Ca}, \mathrm{Mg}, \mathrm{Fe}$, and $\mathrm{Mn}$ carbonate (e.g., McKay et al. 1996) in which nanometer-sized magnetites $\left(\mathrm{Fe}_{3} \mathrm{O}_{4}\right)$ are evenly distributed as a minor phase (McKay et al. 1996; Thomas-Keprta et al. 2001, 2002). Surrounding the core is an inner and outer rim composed mainly of nanometer-sized magnetite crystals embedded in a $\mathrm{Mg}$-rich $\mathrm{FeCO}_{3}$ matrix (e.g., McKay et al. 1996) which are separated by a band of nearly pure $\mathrm{Mg}$-carbonate. Approximately $25 \%$ of the ALH84001 magnetites display 5 of 6 properties that are uniquely characteristic of intracellularly produced biogenic magnetites from magnetotactic bacteria strain MV-1 (Thomas-Keprta et al. 2000, 2001, 2002):

1. Both are single domain

2. Chemically pure

3. Defect free

4. Elongated along the [111] axis

5. Have a three-dimensional geometry described as truncated hexa-octahedral

The sixth property, that of magnetite arranged in chains, has been independently reported by Friedmann et al. (2001) in selected regions of ALH84001. We determined the 3-D geometry of individual ALH84001 and MV-1 magnetite crystals using classical (Fig. 1) and electron tomographic transmission electron microscope (TEM) imaging (Clemett et al. 2002; Thomas-Kepta et al. 2003). The remaining $75 \%$ of the ALH 84001 magnetites do not meet the criteria to be defined as biogenic. They show a variety of physical shapes that can be divided into irregular and regular. Irregular particles have low symmetry with generally poorly expressed crystal faces. Regular particles appear either as whiskers, plates, or equidimensional shapes. These magnetites can also be divided by their chemical composition. Some are chemically pure (stoichiometric $\mathrm{Fe}_{3} \mathrm{O}_{4}$ ) or contain minor to trace levels of $\mathrm{Al}$ and/or $\mathrm{Cr}$. Constraining the origin of these magnetites is hindered because they lack, as a group, any unifying characteristics which are indicative of a given formation process.

The report by McKay et al. (1996) and subsequent papers on ALH84001 magnetite (Thomas-Keprta et al. 2000, 2001, 2002) have not been without controversy. The identification of a population of ALH84001 magnetite identical to magnetite produced by terrestrial magnetotactic bacteria is not in contention. Rather, the debate and surrounding controversy is over whether this truncated 


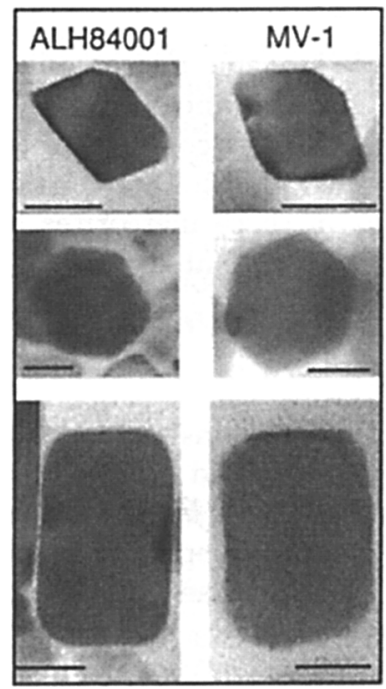

Figure 1. Transmission electron microscope images of truncated hexa-octahedral magnetites extracted from Martian meteorite ALH84001 carbonate globules (left) and corresponding orientations of magnetite crystals produced by magnetotactic bacteria strain MV-1 (right). The scale bars are $20 \mathrm{~nm}$.

hexa-octahedral magnetite is the exclusive product of biology. To date, the most credible alternative inorganic hypothesis is centered on whether partial thermal decomposition of the ALH84001 carbonates could produce a population of biogenic-like magnetite (Golden et al. 2001; Barber \& Scott 2002).

However, there are serious inconsistencies with this hypothesis and thus, this explanation remains unresolved. For example, the decomposition of a solid solution $\left[\left(\mathrm{Fe}_{x} 3, \mathrm{Mg}_{1}-x\right) \mathrm{CO}_{3}\right]$ carbonate, as observed in ALH84001, forms a mixed Fe-Mg spinel (Bagin et al. 1974; Chai \& Navrotsky 1996; Dubrawski 1991) and not pure magnetite, as observed for the truncated hexa-octahedral fraction of the ALH84001 crystals (Thomas-Keprta et al. 2000, 2001). Therefore, although controversial, the biogenic interpretation for a quarter of the ALH84001 magnetites is, and continues to remain, the most plausible hypothesis yet advanced. Additionally, such a biogenic interpretation is consistent with the broader scenario of how the carbonates themselves formed (McKay et al. 1996; Romanek et al. 1994; Treiman \& Romanek 1998; Valley et al. 1997).

\section{Summary}

After six years of extensive study by the world's scientific community, the biogenic hypothesis which argues for biogenic activity on early Mars, still remains a viable explanation. The strongest line of evidence is the presence of truncated hexa-octahedral magnetite within the ALH84001 carbonate globules. To date, 
no credible inorganic explanation has yet been proposed to satisfactorily explain all four lines of evidence.

\section{References}

Bagin, V. I., et al. 1974, Izv. Earth. Phys., 6, 73

Barber, D. J., \& Scott, E. R. D. 2002, PNAS-USA, 99, 6556

Bogard, D., \& Garrison, D. 1998, MAPS, 33, A19

Bradley, J. P., et al. 1996, GCA, 60, 765

Brearley, A. J., 1998 LPSC 29, CD-ROM \#1451

Chai, L., \& Navortsky, A. 1996, GCA, 60, 4377

Clemett, S. J., et al. 1998, Faraday Disc., 109, 417

Clemett, S. J., et al. 2002, Am. Min., 87, 1727

Dubrawski, J. V. 1991, J. Therm. Ana., 37, 1213

Eiler, J. M., et al. 2002, GCA, 66, 1285

Friedmann, E. I., et al. 2001, PNAS-USA, 98, 2176

Gibson, E. K. Jr., et al. 2001, Precamb. Res., 106, 15

Greenwood, J.P., \& McKeegan, K. D. 2002, MAPS (Suppl), 37, A58

Golden, D. C., et al. 2001, Am. Min, 86, 370

Harvey, R. P., \& McSween, H. Y. Jr. 1996, Nature, 382, 49

Jull, A. J. T., et al. 1998, Sci, 279, 366

Jull, A. J. T., et al. 2000, GCA, 64, 3763

Kirschvink, J. L., et al. 1997, Sci, 275, 1629

Kozio, A. M., \& Brearly, A. J. 2002, LPSC, 33, Abst.\#1672 (CD-ROM)

McCollom, T. M., 2003, GCA, (in press)

McKay, D. S., et al. 1996, Sci, 286, 924

Romanek, C. S., et al. 1994, Nature, 372, 655

Steele, A., et al. 2000, LPSC, 31, Abst.\#1670, CD-ROM

Thomas-Keprta, K. L., et al. 2000, GCA, 64, 4049

Thomas-Keprta, K. L., et al. 2001, PNAS, 98, 2164

Thomas-Keprta, K. L., et al. 2002, AEM, 68. 3663

Thomas-Keprta, K. L., et al. 2003, LPSC, 34, Abst.\#1669 (CD-ROM)

Treiman, A. H., \& Romanek C. S. 1998, MAPS, 33, 737

Valley, J. W., et al. 1997, Science, 275, 1633 


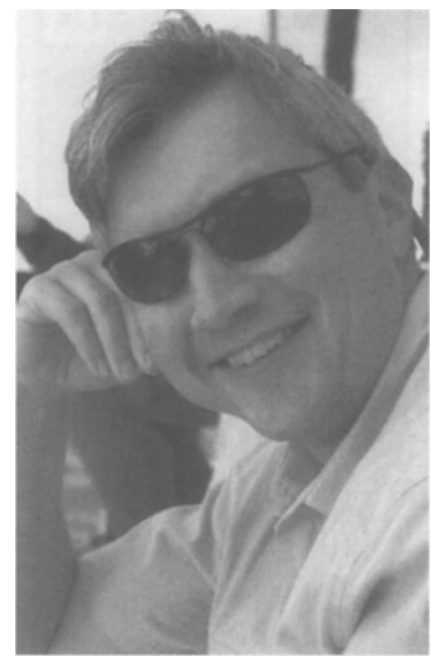

Chris Chyba (photo: Seth Shostak)

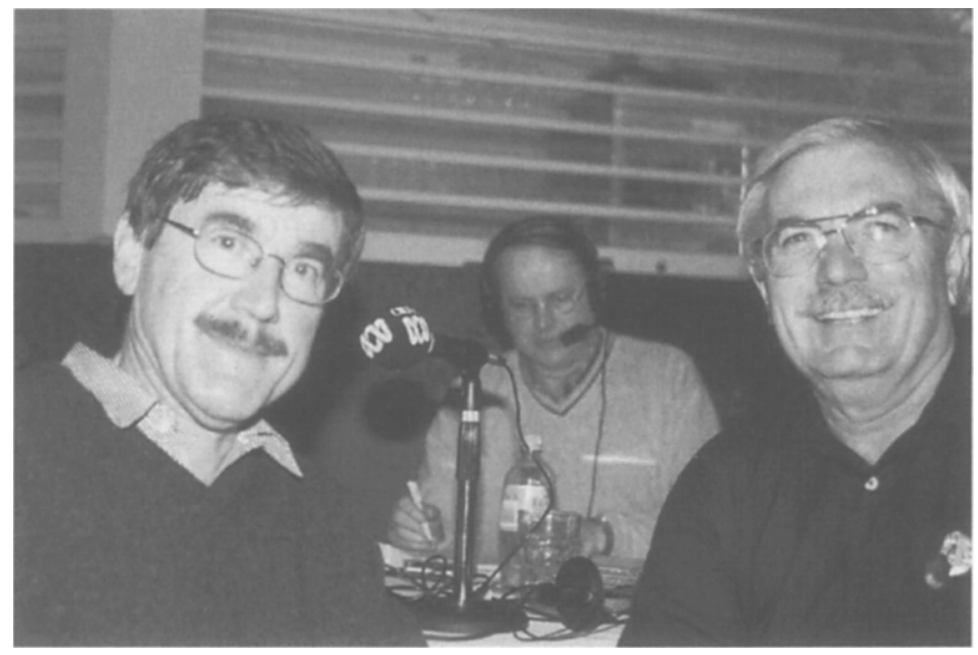

Paul Davies \& Everett Gibson being interviewed by the ABC (photo: Everett Gibson) 